\title{
Carbon black dispersions in surfactant-based microemulsion - CORRIGENDUM
}

Mohamed Youssry, Dominique Guyomard, and Bernard Lestriez

doi: https://doi.org/10.1557/jmr.2017.451, Published by Cambridge University Press, 2 January 2018

In Youssry et al. ${ }^{1}$, the incorrect image was provided for Fig. 5. The correct figure is below.

\section{REFERENCE}

1. M. Youssry, D. Guyomard, and B. Lestriez: Carbon black dispersions in surfactant-based microemulsion. J. Mater. Res. doi:10.1557/jmr.2017.451 (2018).

(b)

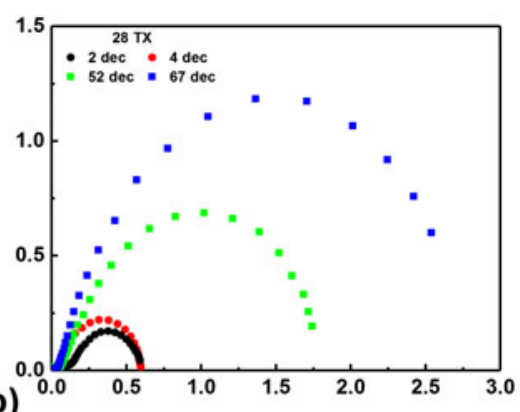

(a)
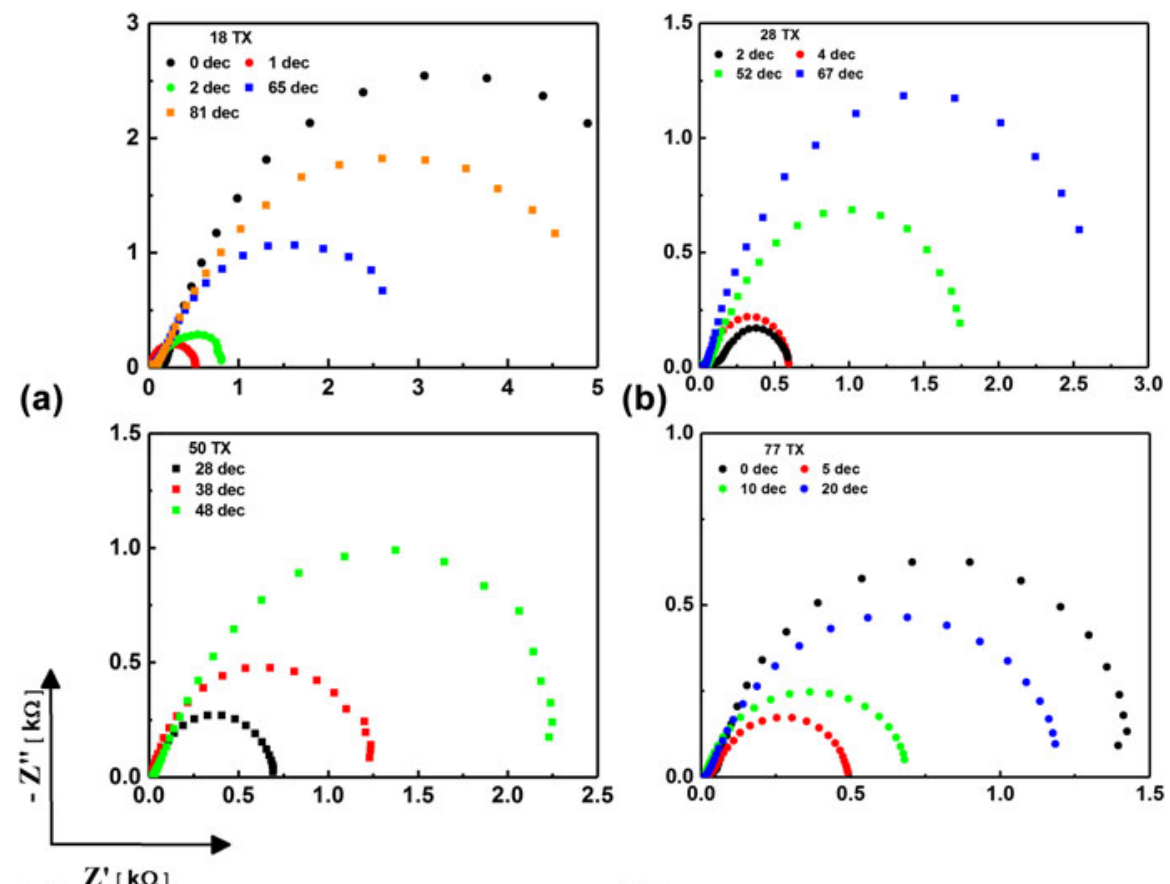

(d)

FIG. 5. Impedance spectra, represented by Nyquist plots (imaginary $Z^{\prime}$ 'versus real $Z$ ' component of impedance), of $2 \mathrm{wt} \% \mathrm{~KB}$ in $\mathrm{L}_{1}$ (circles) and $\mathrm{L}_{2}$ (squares) microemulsions at rest, at $25^{\circ} \mathrm{C}$ (at $100 \mathrm{mV}$ ). 